2. Abbas SA, Zeeshan R, Sultan $S$, Irfan SM. Direct Coombs test positivity in B-chronic lymphoid leukemia: a marker of advanced clinical disease. Asian Pac J Cancer Prev 2015;16:6007-6010.

3. Quinquenel A, Al Nawakil C, Baran-Marszak F, Eclache V, Letestu R, Khalloufi M, Boubaya M, Le Roy C, Varin-Blank N, Delmer A, Levy V, AjchenbaumCymbalista F. Old DAT and new data: positive direct antiglobulin test identifies a subgroup with poor outcome among chronic lymphocytic leukemia stage A patients. Am J Hematol 2015;90:5-8.
4. Quinquenel A, Willekens $C$, Dupuis J, Royer B, Ysebaert L, De Guibert $S$, Michallet AS, Feugier P, Guieze R, Levy V, Delmer A. Bendamustine and rituximab combination in the management of chronic lymphocytic leukemia-associated autoimmune hemolytic anemia: a multicentric retrospective study of the French CLL intergroup (GCFLLC/MW and GOELAMS). Am J Hematol 2015;90:204-207.

5. Hallek M. Chronic lymphocytic leukemia: 2017 update on diagnosis, risk stratification, and treatment. Am J Hematol 2017;92:946-965.

\title{
Demodicidosis Accompanying Acute Cutaneous Graft-Versus-Host Disease after Allogeneic Stem Cell Transplantation
}

\author{
Allojeneik Kök Hücre Nakli Sonrası Akut Graft Versus Host Hastalığına Eşlik Eden \\ Demodisidoz
}

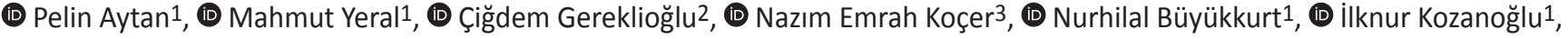 \\ (1) Hakan Özdoğu1, (1) Can Boğa1 \\ ${ }^{1}$ Başkent University Faculty of Medicine, Adana Dr. Turgut Noyan Application and Research Center, Clinic of Hematology, Adana, Turkey \\ ${ }^{2}$ Başkent University Faculty of Medicine, Department of Family Medicine, Adana, Turkey \\ ${ }^{3}$ Başkent University Faculty of Medicine, Adana Dr. Turgut Noyan Application and Research Center, Clinic of Pathology, Adana, Turkey
}

To the Editor,

A 39-year-old female with acute myeloid leukemia was admitted to our transplantation clinic with face eruption without any pruritus. The eruption had occurred 28 days after she underwent an allogeneic hematopoietic stem cell transplantation (SCT). She was allografted with $6.12 \times 10^{6}$ nonmanipulated CD34+ cells from a fully matched sibling donor after a conditioning regimen including busulfan $(12.8 \mathrm{mg} /$ $\left.\mathrm{m}^{2}\right)$, fludarabine $\left(150 \mathrm{mg} / \mathrm{m}^{2}\right)$, anti-thymocyte globulin (30 $\mathrm{mg} / \mathrm{kg}$ ), and total body irradiation (400 Gy/day). Graft-versushost disease (GVHD) prophylaxis comprised methotrexate at $12 \mathrm{mg} /$ day for 3 days and cyclosporine $\mathrm{A}$ at $75 \mathrm{mg}$ twice daily. No recent changes had been made to the medication. Neutrophil and thrombocyte engraftment both occurred on day 11 . The toxicity related to the regimen was mild, being assigned the first grade for oral mucosa according to the Bearman scale [1]. The findings of the physical examination were patchy and confluent erythema of the face, suspicious for cutaneous acute GVHD. There were no other skin changes except that of the palms and soles. Neither intestinal nor hepatic acute GVHD occurred. Laboratory evaluation revealed a white blood cell count of $12,000 / \mu \mathrm{L}$, a hemoglobin level of $11.5 \mathrm{~g} / \mathrm{dL}$, a platelet count of $158,000 / \mu \mathrm{L}$, and an absolute neutrophil count of $8400 / \mu \mathrm{L}$. A 4-mm skin punch biopsy was performed [2]. There were lymphocytes and polymorphic neutrophils that attacked hair follicles and two Civatte bodies. Histochemically Demodex folliculorum was diagnosed with PAS staining within the hair follicles (Figures $1 \mathrm{~A}$ and 1B). Even with lymphocytes attacking hair follicles and Civatte bodies suggesting GVHD, Demodex folliculitis can mimic acute GVHD (Figures $1 \mathrm{C}$ and 1D). Demodicidosis was treated successfully with local 1\% metronidazole and 5\% permethrin. Methylprednisolone was also administered from the beginning of the symptoms and the dosing was reduced by $8 \mathrm{mg}$ every week. The skin eruptions on the face and the neck resolved on day +52 .

Demodex folliculitis after allogeneic SCT is seen rarely and, as far as we know, our case is the sixth reported case $[3,4,5,6]$. The most important differential diagnosis of Demodex folliculitis within the first 100 days after allogeneic SCT is acute GVHD. The infestation by Demodex sp. can be associated with immune suppression. The differential diagnosis of facial erythema after bone marrow transplantation includes acute GVHD, drug eruptions, systemic lupus erythematosus, viral exanthema, toxic erythema of chemotherapy, drug-induced photosensitivity, and photodermatitis [3]. In our case there 


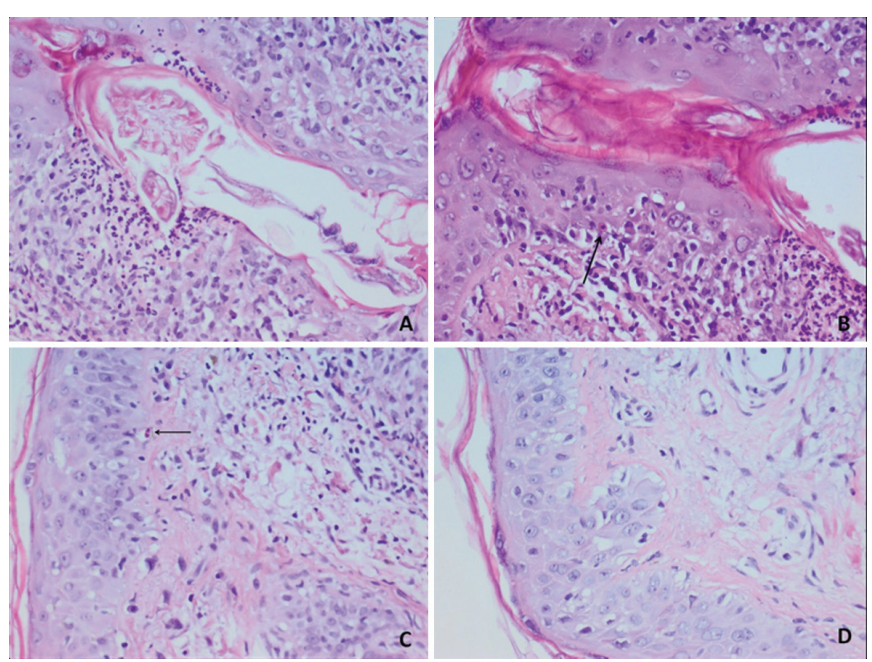

Figure 1. A) Demodex mite; B) Civatte body in the follicular epithelium containing Demodexand lymphocyte exocytosis; C) Civatte body in the epithelium far from the follicle; D) diffuse basal vacuolization in epidermis (periodic acid-schiff staining, magnification 40) (159x119 mm; 72x72 DPI).

were eruptions on the cheek, forehead, and jaw regions, which can be distinguished in both acute GVHD and Demodex folliculitis. However, the development of palmar erythema of the upper extremities is not a feature of demodicidosis. As confirmed by pathological examination, there were findings of both acute GVHD (presence of Civatte bodies, lymphocyte exocytosis, diffuse basal vacuolization in the epidermis) and demodicidosis (presence of Demodex folliculorum).

It should not be forgotten that GVHD may be associated with demodicidosis and Demodex infestation should be remembered in the differential diagnosis of eruptions in patients with hematological malignancies receiving chemotherapy and after SCT. For this reason, when the diagnosis of acute GVHD is ambiguous, an early skin biopsy has to be done after allogeneic
SCT because early therapy for a possible Demodex infestation would prevent the progression of GVHD.

Keywords: Demodex folliculitis, Acute graft-versus-host disease, Post-transplantation

Anahtar Sözcükler: Demodeks follikülit, Akut graft versus host hastalığı, Nakil sonrası

Informed Consent: Informed consent was received from the patient.

Conflict of Interest: The authors of this paper have no conflicts of interest, including specific financial interests, relationships, and/or affiliations relevant to the subject matter or materials included.

\section{References}

1. Bearman SI, Applebaum FR, Buckner CD, Petersen FB, Fisher LD, Clift RA,Thomas ED. Regimen-related toxicity in patients undergoing bone marrow transplantation. J Clin Oncol 1988;6:1562-1568.

2. Hillen $U$, Häusermann $P$, Massi $D$, Janin $A$, Wolff $D$, Lawitschka $A$, Greinix $\mathrm{H}$, Meyer R, Ziemer M. Consensus on performing skin biopsies, laboratory workup, evaluation of tissue samples and reporting of the results in patients with suspected cutaneous graft-versus-host disease. J Eur Acad Dermatol Venereol 2015;29:948-954.

3. Cotliar J, Frankfurt 0. Demodex folliculitis mimicking acute graft-vs-host disease. JAMA Dermatol 2013;149:1407-1409

4. Lotze C, Krüger WH, Kiefer T, Swensson O, Herbst EW, Schüler F, Busemann C, Dölken G. Facial rash mimicking cutaneous acute graft-versus-host disease after allogeneic stem cell transplantation for osteomyelofibrosis: was Demodex the culprit? Bone Marrow Transplant 2006;37:711-712.

5. Aisa Y, Mori T, Tanikawa A, Takae Y, Kato J, Ikeda Y, Okamoto S. Demodicidosis as a cause of facial eruption developing early after allogeneic hematopoietic stem cell transplantation. Transplant Int 2008;21:1192-1193.

6. Román-Curto $C$, Meseguer-Yebra C, Cañueto J, Fraile-Alonso C, Santos-Briz A, Vázquez L, Fernández-López E. Demodicidosis stimulating acute graftversus-host disease after allogeneic stem cell transplantation in one patient with acute lymphoblastic leukemia. Transpl Infect Dis 2012;14:387-390.

\begin{tabular}{lr}
\hline Address for Correspondence/Yazışma Adresi: Pelin AYTAN, M.D., & Received/Geliş tarihi: February 06, 2018 \\
Accepted/Kabul tarihi: July 02, 2018 \\
Baskent University Faculty of Medicine, Training and Research Hospital, Bone Marrow and Stem Cell Transplantation
\end{tabular}

